\title{
Das possibilidades do pesquisar em contextos indígenas de Rondônia ${ }^{1}$
}

\author{
From possibilities of research in indigenous contexts of \\ Rondônia
}

\author{
Jonatha Daniel dos Santos ${ }^{2}$ \\ Rozane Alonso Alves ${ }^{3}$
}

DOI: http://dx.doi.org/10.20435/tellus.v17i33.445

\begin{abstract}
Resumo: O objetivo deste artigo é expor as metodologias e a produção de dados utilizados em duas pesquisas de Mestrado desenvolvidas com os povos indígenas do estado de Rondônia. Assim, propomos neste texto abordar, bem como problematizar, as fontes metodológicas, as articulações realizadas no contexto teórico metodológico das dissertações de mestrado desenvolvidas com povos indígenas de Rondônia. A questão norteadora deste excerto vincula-se às concepções metodológicas na produção de dados e à "descolonização de nós mesmos" no sentido de que ambos os autores sofreram ressignificações no contexto da pesquisa com os povos indígenas de Rondônia. Como possibilidades conclusórias, problematizamos a relação de experiência e vivência com os sujeitos pesquisados no contexto da produção de dados de uma pesquisa de mestrado. A relação com o outro: estar com outro, ouvir, negociar, possibilita ao sujeito pesquisador (a) novas fontes metodológicas e novos olhares sobre o pesquisar.
\end{abstract}

Palavras-chave: infância indígena; etnomatemática; possibilidades metodológicas; povos indígenas de Rondônia.

Abstract: The objective of this article is to expose the methodologies and the data production used in two Master studies developed with the indigenous peoples of the state of Rondônia. Thus, we propose in this text to approach, as well as to problematize the methodological sources, the articulations carried out in the theoretical methodological context of the master dissertations developed with indigenous peoples of Rondônia. The guiding question of this excerpt is linked to

\footnotetext{
${ }^{1}$ Este texto é fruto das dissertações de mestrado dos autores(as) envolvidos e contou com o financiamento da Fundação de Amparo a Pesquisa do Estado do Rio Grande do Sul (FAPERGS), bem como da Capes, via bolsa taxa.

2 Universidade Católica Dom Bosco (UCDB), Campo Grande, Mato Grosso do Sul, Brasil.

${ }^{3}$ Instituto Federal Goiano (IF Goiano), Ipameri, Goiás, Brasil.
} 
the methodological conceptions in the production of data and the "decolonization of ourselves" in the sense that both authors underwent re-significances in the context of the research with the indigenous peoples of Rondônia. As conclusive possibilities, we problematize the relation of experience and experience with the subjects surveyed in the context of the data production of a master's research. The relation with the other: to be with others, to listen, to negotiate, allows to the researcher subject new methodological sources and new looks on the research.

Key words: indigenous childhood; ethnomathematics; methodological possibilities; indigenous peoples of Rondônia.

\section{PALAVRAS INICIAIS}

O caminho a ser percorrido em qualquer pesquisa acadêmica estabelece, inicialmente, alguns objetivos para o seguimento na trajetória do estudo. Dessa forma, concordamos que "a pesquisa é a instauração de um acontecimento que pressupõe uma ativa relação entre os sujeitos que se põem em diálogo, o tema sobre o qual eles dialogam e o contexto no qual esse diálogo se dá" (PEREIRA, 2012, p. 62). No entanto, como ocorrerá esse percurso torna-se a questão norteadora deste excerto.

Mas torna-se primordial, neste trabalho, a compreensão sobre a "descolonização de nós mesmos" (JOAQUIM, 2016) 4 ao produzir dados para a pesquisa. A partir dessa fala do companheiro indígena Joaquim Adiala Hara, é possível compreender que, como pesquisadores e pesquisadoras, devemos incessantemente colocar sob-rasura os modelos tradicionais de fazer pesquisa e produzir dados. Entendemos, como modelo tradicional, aquelas técnicas e objetos que se fazem neutros no contexto do pesquisar, ou seja, aquela que cria uma instância de neutralidade do eu "pesquisador" com o outro "colaborador". Além disso, tende-se a buscar a objetividade por meio do disciplinamento científico, em que, se utilizando do método, presume-se que o resultado é questão de tempo.

É preciso a "descolonização de nós mesmos" a fim de não cair da armadilha da essencialidade e, por meio dela, produzir pesquisas binárias, fixas, retratadas em moldes e técnicas que podem sugerir um resultado que, talvez, não seja condizente com a realidade. Por isso a importância de reflexão-ação-reflexão no contexto da

\footnotetext{
${ }^{4}$ Discussão em aula na disciplina "Seminário de Orientação Coletiva", no dia 06/04/2016, no âmbito do Programa de Pós-Graduação em Educação da Universidade Católica Dom Bosco (UCDB).
} 
pesquisa. Também é preciso problematizar sobre o discurso hegemônico e considerar a necessidade de reflexão no que condiz ao olhar o outro a partir do olhar pessoal, olhar colonizado, que por vezes ainda subentende uma marginalização do outro, o que recai no que se denomina por Etno/centrismo. Acreditamos que se a "verdade" foi criada, logo pode ser ressignificada e problematizada.

Os conflitos, as tensões da pesquisa também são produzidas no interior das relações que são estabelecidas entre pesquisadores (o contexto individual, os significados, as representações atribuídas, os olhares, as identidades, as representações mútuas a respeito um do outro).

Assim, o investigador não vai transformar uma determinada realidade, um determinado contexto, um determinado sujeito ou grupo social. Por outro lado, poderá discutir articular, questionar, fazer emergir a pluralidade das questões pesquisadas, não como conclusivas, mas sempre em movimento. São princípios que entendemos ser necessários para pesquisar o outro e com outro.

A esse respeito, é importante trazer Skliar (2003) ao tratar da mesmidade e da outridade. Muito mais que reconhecer a existência do outro, do diferente, do próprio sujeito como o outro, é preciso deixar de ver o outro como fonte de todo mal (SKLIAR, 2003). É preciso estar/fazer parte do contexto e ir ao encontro do outro como sujeito que pertence a este mundo, que autentica o próximo por meio da sua diferença. O outro como fonte de todo mal, ou até mesmo a demonização do outro como nos afirma Skliar e Deschatzky (2001, p. 121) constituída pela modernidade "são estratégias de regulação da alteridade e de controle da alteridade que, só em princípio, podem parecer sutis variações dentro de uma mesma narrativa". Entre elas, "sua transformação em sujeito ausente, quer dizer, a ausência das diferenças ao pensar a cultura, a delimitação e limitação de suas perturbações, sua invenção para que dependa das traduções oficiais" (SKLIAR; DESCHATZKY, 2001, p. 121).

Dessa forma, na próxima seção propomos apresentar duas pesquisas de mestrado bem como os recursos metodológicos utilizados para a produção de dados, ao tempo que expomos brevemente o seu desenvolvimento no contexto de pesquisa. Entendemos que, para melhorar a leitura, os dois tópicos a seguir são os títulos dos trabalhos que se constituíram nas dissertações defendidas, a primeira em julho de 2014, a segunda em agosto de 2015. 


\section{INFÂNCIA INDÍGENA: NARRATIVAS DAS CRIANÇAS ARARA-KARO NA REGIÃO AMAZÔNICA ${ }^{5}$}

A dissertação de mestrado buscou compreender como as crianças indígenas Arara-Karo (Povo Indígena residente da Terra Indígena Igarapé Lourdes que fica no município de Ji-Paraná, Estado de Rondônia) narram-se indígenas. Para tanto, contei com a participação de cinco crianças da etnia Arara-Karo, sendo duas meninas e três meninos. Ambas as crianças estudam em escolas estaduais do Município de Ji-Paraná, Rondônia. A etnia Arara-Karo tem duas aldeias, Paygap e I’Terap. Todas as crianças indígenas residem na zona urbana de Ji-Paraná, mas continuam tendo suas casas na aldeia I'Terap. A grande questão desta pesquisa esteve relacionada ao olhar para si das crianças indígenas.

Em Alves (2014), ao repensar a metodologia adotada na pesquisa, por meio da leitura de Larrosa (2011), propusemos olhar as crianças indígenas que participaram desta pesquisa, experimentarmos-nos a partir das nossas próprias narrativas, do ver-se, do olhar-se, das expressões que fazemos de nós mesmos. Buscamos em Sarmento (2011), quando trata do como as crianças olham para o mundo e explica "os olhos com que veem esse mundo têm a limpidez e a perturbação dos primeiros olhares; é por eles que descobrem objectos, nexos e sentidos que não é legítimo de modo algum menosprezar" (SARMENTO, 2011, p. 55).

Para a produção de dados da pesquisa, os desenhos, as fotografias e as entrevistas fizeram parte do trabalho. Por meio dos escritos de Cunha (2013) sentimo-nos inspirados a olhar os desenhos, as fotos, referente à relação que as crianças estabelecem enquanto "linguagem expressiva entendida aqui como uma forma de ler e representar suas relações singulares com o mundo".

Nas entrevistas, trazemos como suporte, a discussão de Andrade (2012) que nos apresentou e encantou com as novas possibilidades de desenvolver pesquisa utilizando as entrevistas narrativas ressignificadas. Também utilizamos os trabalhos realizados com as crianças, presentes no repositório digital da biblioteca da UFRGS, bem como em pesquisas que apontam para outras perspectivas teórico-metodológicas e que trazem como suporte, fotografias e desenhos de crianças pesquisadas.

\footnotetext{
${ }^{5}$ Título da dissertação de Rozane Alonso Alves - Pesquisadora do Grupo de Pesquisa em Educação na Amazônia (GPEA), e do Grupo de Pesquisa Interculturalidade e Educação (GPEIN). A dissertação em questão está vinculada ao Programa de Pós-Graduação em Educação da Faculdade de Educação da Universidade Federal do Rio Grande do Sul (UFRGS).
} 
O uso das fotografias foi utilizado como recurso para o fazer falar das crianças indígenas, o que possibilitou que elas pudessem narrar-se e dizer sobre si, falar sobre as experiências que as tocavam. Auxiliaram-nos também, como pesquisadoras, a entrar no mundo das crianças indígenas Arara. As fotografias tiradas pelas crianças Arara, de algum modo, indicaram caminhos de pesquisa, mostrando o norte que ela deveria tomar. "A fotografia, por sua vez, além de compor parte do texto reconstruindo o próprio olhar do investigador, apresentando-se como outras possibilidades de escrita - outros textos - da realidade estruturada" (MARTINS FILHO; PRADO, 2011, p. 98).

Também foram utilizados os desenhos das crianças, entendendo-os naquilo que ensina Sarmento (2011, p. 55) "O desenho das crianças é, afinal, o desenho de um mundo" do seu mundo, continuamente reinventado, recriado pela inventividade das crianças. No que se refere ao uso dos seus desenhos, ou mesmo ao propor os desenhos como forma de autorretratos, não se imaginava que estes e as posições sociais das crianças expressas por meio dos desenhos caminhariam da forma como ocorreram. Fomos bastante questionadas pelas crianças sobre como eles autorizariam a participarem da pesquisa; assim, o Homem Aranha (auto-nominação de um dos meninos) se posiciona firmemente ao contradizer a ideia de que sua autorização não é válida perante o comitê de ética da universidade. Questiona como, ao tempo que ele autoriza o uso de seu nome verdadeiro na dissertação, seu nome não pode aparecer na pesquisa. Assim, ao pedir o seu autorretrato, ele se apresenta com o nome que escolheu para se apresentar na dissertação (Homem Aranha).

Ficamos atentas às suas vozes, concepções de mundo, e relações que estas estabeleciam dentro e fora da escola, à forma como dizem sobre o ser indígena: como se veem e falam de si. Para tanto, os enredos metodológicos, os suportes para dizer sobre si nesta pesquisa, o cerne da metodologia apresentada junto às crianças indígenas está relacionado às questões que norteiam o conceito de experiência, como nos afirma Larrosa (2011), quando ensina que os sujeitos se constituem por meio da experiência, aquilo que nos toca, passa, aquilo que nos acontece, nos transforma enquanto sujeitos da experiência, que inscreve marcas, deixa vestígios, efeitos. Trazemos, como suporte, a discussão de Andrade (2012), que nos apresentou e encantou com as novas possibilidades de desenvolver pesquisa utilizando as entrevistas narrativas ressignifcadas.

Quanto às entrevistas- um dos meios de produção de dados, foram utilizadas as entrevistas narrativas, usando-as como uma possibilidade de pesquisa ressignificada 
no campo da pesquisa pós-estruturalista, em uma perspectiva etnográfica, tomando como base de produção de dados, como citado anteriormente, as pesquisas de Andrade (2012), visto que a autora auxilia a compreender as narrativas como narrativas de si. Conceituando-a como "[...] a compreensão de que cada pesquisador/a, na relação com o/a outro/a, ressignifica o fazer metodológico em sua trajetória pessoal de investigação. [...] A produção do sujeito se dá no âmbito da linguagem, na relação com as forças discursivas que o nomeiam e governam, sendo a escola um desses locais da cultura no qual se produz e se nomeia o sujeito [...] (ANDRADE, 2012, p. 174).

Quando se trata de pesquisas com crianças indígenas, descobrimos que não podia apresentar uma metodologia dada como certa e consistente, entendemos que, para realizar uma pesquisa com essas crianças, a princípio, deveria se apresentar a elas a proposta de estudo e, junto com elas, inventar o melhor meio investigativo para suscitar a produção de dados da pesquisa. Concordamos com Tomás (2011 , p. 144) quando afirma que é preciso utilizar "dispositivos metodológicos e analíticos adequados" às crianças.

Os dispositivos metodológicos e analíticos, no que se refere à pesquisa com as crianças indígenas de Ji-Paraná, $\mathrm{RO}$, foram construídos a partir da interação entre pesquisadora e pesquisados, que, ao mesmo tempo, tornam-se pesquisadores e pesquisadoras. Permitindo aos sujeitos da pesquisa que trocassem de lugar, uma vez que as crianças inseridas na pesquisa se tornassem pesquisadores/as, a investigação com crianças trata-se de um "processo dialógico entre investigadores da infância, destes com as crianças e entre crianças, numa dinâmica de diálogo, partilha e confronto de saberes diferentes, mas complementares" (TOMÁS, 2011, p. 132).

A partir dessas possibilidades metodológicas, foi possível perceber que as brincadeiras realizadas pelas crianças indígenas se juntam aos mitos e às histórias do povo Arara. As crianças indígenas transitam entre as relações que estabelecem com os rituais que elas vivenciam e presenciam e sua cotidianidade. As crianças indígenas Arara criam aprendizagens por meio das brincadeiras, das experiências rituais das histórias contadas pelo Pajé que só são possíveis de ser aprendidas, capturadas pela fala do Pajé, pois ele é quem conhece, quem vivenciou os rituais e os mitos e se apropriou dessas vivências e agora compartilha com os mais jovens a história do povo Arara. As crianças indígenas, nesse caso, vão estabelecendo entre si uma relação de "complementaridade, refletindo momentos de interiorização e 
de exteriorização, de concentração e de expansão, de descoberta e de reafirmação, de vivências individuais e coletivas, por certo necessários a um desenvolvimento necessário e pleno" (NUNES, 2002, p. 78).

É interessante apontar também que, por meio desses aportes metodológicos, partilhamos das experiências que as crianças Arara tiveram referente aos sentimentos e emoções em relação à escola, aos seus pares, às amizades, aos namoros e como estas relações estabelecidas os constituíram e como, por meio deste emaranhado de sentimentos, elas diziam de si. Foram esses aportes que possibilitaram perceber essas narrativas que elas apresentaram ao longo da dissertação de mestrado. As experiências que as crianças Arara da pesquisa, foram acumulando em relação às suas emoções e sentimentos as permitiam distinguir e, se necessário, distanciar a "amizade e o amor - como dependerão, também, da aprendizagem dos diferentes conceitos emocionais que permitem, não apenas o seu reconhecimento como a sua distinção relativamente a emoções distintas" (TREVISAN, s.d., p. 7), optando pela relação que faz mais sentido a elas, colocando essas situações em patamares diferentes e se apropriando dos conhecimentos que foram adquirindo para propor novas relações de amizade, de amores e de escolhas.

Diante de alguns apontamentos realizados frente à questão do pesquisar com os povos indígenas de Rondônia, neste caso, com as crianças Arara-Karo, percebemos o quanto durante a produção dos dados (toda pesquisa) para a feitura da dissertação as crianças indígenas Arara-Karo foram apresentando novos caminhos a serem seguidos. É interessante apontar que a dissertação em questão se constitui no campo dos estudos pós-estruturalistas, tendo como base teórica os estudos foucaultianos.

Nesse sentido, os estudos foucaultianos permitiram durante a pesquisa o deslocar, o desenquadrar, ou seja, permite, segundo os estudos foucaultianos, a se fazer sujeito por meio da escrita, em que constituímos nos (des)caminhos da pesquisa, o "meu si mesma" e os dos outros, no caso o "si" das crianças indígenas. As leituras em Foucault (1985) ajudaram a pensar que o mais importante é entender que existem múltiplas verdades para determinados acontecimentos; observar as relações que se estabelecem enquanto relações de força, afinal de contas nos constituímos enquanto história e, ao mesmo tempo, a constituímos.

Apropriamo-nos, ou tentamos nos apropriar do que ensina Foucault (1979), quando trata da genealogia. Para o autor existem outras formas de olhar e estar no mundo, de analisar a história e se afastar dessa enquanto verdades dadas, tendo em 
vista que, o sujeito é efeito do poder, não existe o outro do poder, existem relações de poder. Não existe status de dominação, existem estados de dominação sempre possíveis de mudança, o que Foucault denomina como resistência. É possível pensar a partir dos conceitos foucaultianos outros pontos de vista sobre as práticas pessoais que se produzem nos espaços escolares e nos sujeitos que o frequentam. Pensar talvez nas resistências das crianças indígenas, nas subjetivações que esse espaço fabrica nessas crianças.

Naquilo que fomos observando, fomos aprendendo com elas (as crianças Arara-Karo) sobre o como funciona para essas crianças o "confrontar", o silêncio, as falas, as narrativas e os gestos que se apresentam como modo de resistência. Foucault ensina que sessa relação de poder se dá mediante o dirigir a conduta do outro. Essas relações são móveis, podem modificar-se, sendo reversíveis e instáveis, ocorrendo, portanto, entre sujeitos livres. Assim como Foucault, pensamos em como funciona o poder que se estabelece nessas relações entre indígenas, entre indígenas e não indígenas e, portanto, das (in)visibilidades dos sujeitos a serem pesquisados.

Pergunta-se: como funcionam essas resistências nas crianças indígenas que frequentam as escolas urbanas de Ji-Paraná? Também havia a preocupação em questionar as estratégias utilizadas como disciplinamento dos corpos dessas crianças. Pensar sobre disciplinamento remete novamente a Foucault (1979) quando nos ensina que talvez o objetivo, hoje, não seja descobrir o que somos, mas recusar o que somos dentro das verdades do outro. Nesse caso, o pressuposto mais relevante dentro do "descobrir o que somos" - pesquisadora e a própria pesquisa, é pensar a existência de si, enquanto verdades que não são absolutas, não são enquadradas. Seria o caso de problematizar as situações que são postas pela e na pesquisa. Como é que o pesquisador vê seu objeto de pesquisa? Assim ele diria: Me vejo assim, ligado à experiência do olhar, dos múltiplos olhares, dos diferentes olhares que adentram minhas inquietações. Meus olhares se multiplicam, mas algo me fez olhar da forma como vejo. Existe agora, um relativismo do olhar, mas essa posição do olhar sobre a criança-estudante-indígena está voltada para o lugar de onde ela fala - das suas escolhas, crenças e conceitos que o constituem como sujeito.

Os procedimentos metodológicos utilizados na produção de dados, no fazer falar das crianças, apontaram que as "formas de narrar a alteridade são, ao fim e ao cabo, formas de tradução e de representação que diluem conflitos e que delimitam os espaços por onde transitar com relativa calma" (DUSCHATZKY; SKLIAR, 2001, p. 122). 
Nas narrativas das crianças Arara, não se percebem olhares idealizados, pois elas com seus pares (outras crianças indígenas e não indígenas) brincam, conversam, produzem relações, esquematizam amizades, brigam por amores, por suas paixões, retomam amizades que foram rompidas por brigas. Não se percebem nessa relação sujeitos ausente de identidade, mas a presença de cada um com suas representações de si mesmo e do outro, com suas marcas culturais, seus artefatos, com tudo que dizem delas nessas relações com seus pares. Dá-se, desse modo, visibilidade às identidades das crianças, tanto a não indígena quanto a Arara, cada uma com suas características, com seus modos de ser, com suas posições políticas e históricas que as produzem e por elas são produzidas.

Por meio desses suportes teóricos e metodológicos, as crianças se dispuseram, se entregaram à pesquisa. Seus desenhos e fotografias narram suas vidas, suas experiências, ou seja, narram as crianças indígenas. Percebe-se nas narrativas das crianças indígenas Arara-Karo seu posicionamento político e social, pois elas se dispõem a lutar por suas comunidades. Elas, as crianças Arara-Karo, também discutem as questões de gênero, o papel da mulher, do homem, da criança menina, da criança menino e mostram que é preciso pensar, problematizar os papéis sociais que cada um desses sujeitos representam para a comunidade. Não seria possível pensar diferente? Esta é a grande questão que as envolve. Outra fala presente nas narrativas das crianças se refere à presença na ausência frente às decisões e posições assumidas pela comunidade, pois elas, as crianças, não votam, não podem decidir a vida da aldeia mesmo sendo, também, parte da comunidade e da aldeia. É maravilhoso o que elas nos mostram, é encantador estar com elas.

\section{SABERES ETNOMATEMÁTICOS NA FORMAÇÃO DE PROFESSORES INDÍGENAS DO CURSO DE LICENCIATURA INTERCULTURAL NA AMAZÔNIA ${ }^{6}$}

Este estudo teve como objetivo analisar como as práticas e os saberes etnomatemáticos expressos pelos indígenas da Amazônia são pensados na formação dos professores indígenas, especificamente, no curso de Licenciatura em Educação Básica Intercultural da Universidade Federal do Rondônia, Campus de Ji-Paraná.

\footnotetext{
${ }^{6}$ Título da dissertação de Jonatha Daniel dos Santos - Pesquisador do Grupo de Pesquisa em Educação na Amazônia (GPEA) e do Grupo de Pesquisa Interculturalidade e Educação (GPEIN). A dissertação está vinculada ao Programa de Pós-Graduação em Educação em Ciências e Matemática da Faculdade de Física da Pontifícia Universidade Católica do Rio Grande do Sul (PUC-RS).
} 
Participaram, como sujeitos de pesquisa, acadêmicos do curso de Licenciatura em Educação Básica Intercultural que optaram pelo eixo Ciências da Natureza e Matemática Intercultural. Tais sujeitos representam as etnias: Suruí-Paiter, Gavião Ikolen, Oro Win, Cinta Larga e Oro Waje, e à época todos eram professores de suas comunidades, nos anos iniciais e finais do Ensino Fundamental.

Para compor o material empírico, foram realizadas entrevistas narrativas durante o mês de fevereiro e março de 2014. Sobre tais narrativas, Santos (2015) realizou uma análise genealógica do discurso considerando aspectos como: o tratamento dado às práticas de indígenas da Amazônia durante a formação dos professores indígenas participantes dessa pesquisa; os conceitos de Etnomatemática que estão presentes no processo de formação desses professores; as implicações da Etnomatemática para as suas práticas escolares.

Com o intuito de alcançar o objetivo proposto na pesquisa ora abordada, de analisar como as práticas e os saberes etnomatemáticos expressos pelos indígenas da Amazônia são pensados na formação dos professores indígenas do curso de Licenciatura em Educação Básica Intercultural da Universidade Federal de Rondônia, Campus de Ji-Paraná, optou-se por realizar um estudo tendo como base o método genealógico de Foucault (1979).

De acordo com Paraíso (2012, p. 25), "[...] com a compreensão mais livre que temos de metodologia, podemos dizer que [...] a genealogia [...] que Foucault tomou de Nietzsche para fazer suas análises históricas [...] são métodos de pesquisa" uma vez que "[...] oferecem tanto modos específicos de interrogar como estratégias para descrever e analisar".

Ainda que Michel Foucault não tenha em nenhum momento constituído suas teorias enquanto método de pesquisa (PARAísO, 2012, p. 25), os estudos pós-estruturalistas vêm constituindo esse método como estratégias para problematizar e colocar "sob rasura" as investigações ressignificando as práticas existentes e inventar outros percursos na pesquisa. O método de Foucault (1979) (de inspiração Nietzschiana), segundo Meyer (2012, p. 54), se dá pela validação do conhecimento científico apresentado pela ciência enquanto uma verdade legitimada, uma vez que "[...] um dos mais poderosos regimes de verdade de nossa época é a Ciência, com C maiúscula".

As pesquisas em educação que assumem uma perspectiva pós-estruturalista, buscam ressignificar essa validação do conhecimento científico entendendo que não 
há uma verdade dada e absoluta que constitui as investigações acadêmicas. A esse respeito, Meyer (2012, p. 54) ressalta que:

[...] admitir que nossas pesquisas também não permitem o acesso à verdade. Elas permitem a descrição, a análise, a problematização e/ou a modificação de verdades contexto-dependentes. Operar com essa noção supõe considerar toda verdade como sendo contexto-dependentes, o que envolve problematizá-las como verdades sancionadas e aceitas, no contexto de determinadas redes de poder.

Essas redes de poder permitem a compreensão da metodologia no campo pós-estruturalista como "[...] caminhos a percorrer, de percursos a trilhar, de trajetos a realizar, de forma que sempre têm por base um conteúdo, uma perspectiva ou uma teoria" (MEYER; PARAíSO, 2012, p. 15). Tais caminhos metodológicos não carregam em si a verdade da pesquisa, mas os contextos que a constituem, que as permitem no fazer metodológico, uma vez que o método de pesquisa se refere sempre a um como fazer (MEYER; PARAÍSO, 2012).

Nesse sentido, esta pesquisa buscou ancorar-se no método genealógico de Michel Foucault, tendo como base as premissas pós-estruturalistas. Ainda, para a produção de dados, as entrevistas narrativas ressignificadas de Andrade (2012) foram o suporte para o fazer falar dos sujeitos então participantes. Para melhor compreensão do método de pesquisa, bem como da produção de dados, será apresentado, primeiramente, o método genealógico, dando sequência, as entrevistas narrativas ressignificadas de Andrade (2012).

Conforme Foucault (1979, p. 172), a genealogia seria, portanto, "com relação ao projeto de uma inscrição dos saberes na hierarquia de poderes próprios à ciência, um empreendimento para libertar da sujeição os saberes históricos, isto é, torná-los capazes de oposição e de luta contra a coerção de um discurso teórico, unitário, formal e científico.

Assim, o método genealógico trata de analisar o que está por trás do discurso, nas entrelinhas, trazendo à tona as condições de possibilidades desse e não de outro discurso. Segundo Veiga-Neto (2007, p. 57), “[...] o maior compromisso da genealogia é com a priori histórico". Ressalta que a genealogia pode ser compreendida enquanto um "[...] conjunto de procedimentos úteis não só para conhecer o passado, como também, e muitas vezes principalmente, para nos rebelarmos contra o presente" (VEIGA-NETO, 2007, p. 59). Complementa: 
Além disso, é preciso atentar para o fato de que se aquilo que a genealogia quer descrever é a antítese das essências, o que se tem de fazer [...] é mapear as ascendências, na forma de condições de possibilidade para a emergência do que hoje é dito, pensado e feito. A genealogia evita proceder como é mais comum, a saber, a partir da fixação de um objeto no presente, para depois ir ao passado, na tentativa de descobrir seu fundamento originário, a fim de chegar à sua suposta origem originalmente original.

Nos dizeres de Veiga-Neto (2007, p. 60), a genealogia não se propõe a criar outra análise e/ou interpretação, mas busca mostrar que "[...] as verdades históricas descansam em um terreno complexo". Foucault (1979), quando trata da genealogia, escreve que existem outras formas de olhar e estar no mundo, de analisar a história e se afastar dessa enquanto verdades dadas, tendo em vista que o sujeito é efeito do poder, não existe o outro do poder, existem relações de poder. Não existe status de dominação, existem estados de dominação sempre possíveis de mudança, o que Foucault (1979) denomina como resistência.

Esta pesquisa de dissertação busca, no método genealógico, analisar os discursos e os olhares instituídos pelos professores/estudantes indígenas frente suas narrativas sobre ser professor, sobre sua prática docente em relação ao curso de Licenciatura em Educação Básica Intercultural e as discussões em torno dos saberes matemáticos tradicionais.

Em relação à entrevista narrativa ressignificada, Andrade (2012, p. 174) afirma que é a própria compreensão de si, uma vez estas permitem "[...] a compreensão de que cada pesquisador/a, na relação com o/a outro/a, ressignifica o fazer metodológico em sua trajetória pessoal de investigação". Para a autora esse tipo de entrevista permite ao sujeito participante da pesquisa narrar fatos, situações e acontecimentos que os tocaram, que têm e fazem sentido para os entrevistados.

Nesse sentido, "por meio das narrativas" capturadas em função da entrevista "[...] é possível reconstruir as significações que os sujeitos atribuem" ao passado, as suas experiências de vida, nesse caso, da docência, do processo de escolarização, entre tantos outros ditos pelos professores/estudantes indígenas que fazem parte desta dissertação, pois, a partir dessas experiências narradas, os participantes "[...] falam de si, reinventando o passado, ressignificando o presente e o vivido para narrar a si mesmos" (ANDRADE, 2012, p. 174).

Assim, as entrevistas narrativas ressignificadas possibilitam ao professores/ estudantes indígenas a narrar-se a partir das experiências vividas no âmbito do 
curso de Licenciatura Intercultural, bem como nas relações estabelecidas durante seu processo de escolarização, uma vez que essas "[...] experiências constituem-nos e são produzidas e mediadas no interior de determinados espaços como a escola ou os espaços que remete às experimentações nela conhecidas" (ANDRADE, 2012, p. 175). A partir das experiências, os professores/estudantes indígenas narram em seus ditos as relações de poder que produziram esse e não outro discurso. Além disso, possibilitam polissemias, ou seja, "[...] não permitem uma ou outra verdade sobre as coisas e os fatos, mas pode-se considerá-las como a instância central que, somada a outras, traz informações fundamentais acerca do vivido e possibilita uma interpretação" (ANDRADE, 2012, p. 175) do sujeito quem ao narrar-se possibilita ao outro da escuta, "visibilizar as coisas ditas e não ditas, mas que se encontram implícitas em tais narrativas" (p. 178).

Desse modo, as "[...] narrativas não constituem o passado em si, mas sim aquilo que os/as informantes continuamente (re) constroem desse passado, como sujeitos dos discursos que lhes permitem significar suas trajetórias" (ANDRADE, 2012, p. 176) de vida pessoal e profissional. E ainda, "[...] essa perspectiva exige, enfim, que se dê conta de uma exploração minuciosa dos textos das narrativas, buscando visibilizar as coisas ditas e não ditas, mas que se encontram implícitas em tais narrativas" (ANDRADE, 2012, p. 179).

Com base nessas perspectivas, os procedimentos de investigação e análise desta então desenvolvidos ancoraram-se na genealogia como método de pesquisa e de análise, e a entrevista narrativa ressignificada como produtora de dados, entendendo que essa perspectiva permite a aproximação com os participantes envolvidos, bem como possibilita a esses sujeitos serem também pesquisadores de seus próprios discursos.

Todas as entrevistas foram realizadas no espaço da Universidade, uma vez que os estudantes/professores indígenas, ao se encontrarem em Ji-Paraná, necessitam alugar residências em parceria com outros colegas em função de tempo (de 45 a 90 dias). Desse modo, não seria adequado realizar uma entrevista em um espaço onde se encontravam aproximadamente cinco a sete pessoas. Outro fator que motivou a pesquisa ser realizada no espaço da Universidade se deu pela timidez explicitada por alguns, bem como a proximidade que eles poderiam querer manter na pesquisa. Das seis entrevistas, cinco foram realizadas nas salas de aula, e uma realizada embaixo de uma árvore. Vale salientar que a opção do local de entrevista foi dos entrevistados. 
As conversas surgiram sempre a partir de uma pergunta central: me fale como você chegou na docência. Ao serem questionados sobre os processos que os constituíram como educadores indígenas, iniciaram suas falas lembrando-se de como foram alfabetizados, de seus professores, da escola e logo (talvez em função de saberem os objetivos da pesquisa) falavam sobre qual Matemática aprenderam, e como foram ensinados, e como isso influenciou na forma como deram aula até ingressarem no curso de Licenciatura Intercultural.

A partir desses relatos, foi possível ir organizando os direcionamentos em relação às experiências evidenciadas pelos colaboradores. Lembrando sempre que, por meio das entrevistas narrativas, a intenção era a narração de suas vivências enquanto educadores para que, a partir das suas falas, fosse possível compreender como constituíam suas percepções em relação às disciplinas mencionadas anteriormente e como isso influenciava em sua prática e em seu modo de entender as implicações dos saberes tradicionais matemáticos no âmbito do curso de Licenciatura Intercultural, bem como em relação ao que conhecemos como Matemática (Matemática não indígena) tanto no âmbito do curso quanto no processo de escolarização.

As entrevistas apontaram que os saberes etnomatemáticos dos povos indígenas, participantes desta dissertação, se constituem enquanto mecanismo de governamento e contraconduta na formação docente dos estudantes professores indígenas no que se refere aos saberes matemáticos desses povos, bem como sua discussão com os estudantes no espaço da escola indígena.

Os relatos indicam que a Etnomatemática vem funcionando nesse espaço como uma estratégia de contraconduta, uma vez que os professores/estudantes indígenas constituem, em relação ao Estado, outro modo de conduzir-se e de conduzir o outro (estudantes das escolas indígenas) por meio de suas práticas docentes. Tais práticas estão em função de sua formação no Curso de Licenciatura Intercultural que, durante o curso, aprofundam a discussão acadêmica em torno dos saberes indígenas e sua funcionalidade na escola, na ressignificação de seus saberes junto aos mais jovens que se inserem nas salas de aula e dela se apropriam para conhecer tais saberes por meio da prática docente do professor indígena.

É interessante apontar que a opção por lente foucaultianas possibilitou a emergência de considerações ainda não apontadas acerca do curso de Licenciatura em Educação Básica Intercultural e modo como este aborda os saberes matemáticos e se utiliza da Etnomatemática como um dispositivo de contraconduta. 
Tais possibilidades metodológicas possibilitaram a análise das narrativas dos professores/estudantes indígenas desse curso, criando condições para compreender que o processo de formação docente desses acadêmicos vem permitindo-lhes o aprofundamento do pensamento matemático tradicional do seu povo em sala de aula. Tais aprofundamentos produzem sua inserção na pesquisa acadêmica e, a partir dela, novos olhares são lançados à cultura.

Com a inserção dos saberes indígenas no processo de formação intercultural dos professores/estudantes indígenas, a compreensão dos conceitos referente à Etnomatemática e a discussão em torno dela na prática docente, produz no corpo pedagógico do professor mecanismos de disciplinamento de sua prática docente e, ao mesmo tempo, dispositivos de contraconduta. Para os sujeitos de pesquisa esse processo não ocorre de forma mecânica, assistencialista do ponto de vista colonizador, tampouco de resistência, contudo vem buscando romper com a estrutura educacional apresentada pelo Estado por meio do currículo oficial que é organizado para escolas não indígenas.

Reafirma-se: "vem buscando" por compreender que esse posicionamento está em constante ressignificação em relação ao envolvimento de diferentes saberes no espaço da escola indígena. Isso vem à tona por meio das narrativas analisadas, as quais evidenciam como ambos os saberes e seus modos e mecanismos de fazer funcionar a matemática têm papel relevante na organização em suas comunidades indígenas.

Por um lado, utilizam-se do saber matemático oficializado no currículo para venderem seus produtos, comprar outros produzidos e vendidos na cidade, fazendo uma relação com capital econômico. Além disso, para entender como funcionam instrumentos que utilizam, mas que anteriormente não faziam parte de seus artefatos culturais, como relógios, calendários, celulares, entre outros.

As próprias lutas políticas necessitam da compreensão desse saber matemático oficializado, pois, para a demarcação da terra, é preciso compreender os números, os meios de demarcá-las por quilômetro quadrado, entre outros. É Evidente em suas narrativas uma funcionalidade do saber matemático ocidental para e na cultura.

Por outro lado, o saber tradicional matemático se vincula à cultura, à problematização e à inserção do pensamento matemático por meio dos mais velhos, ou das relações que se estabelecem entre os mais novos e os mais velhos por meio desse saber. Essas questões ressignificam o saber, bem como o lugar que ocupa cada sujeito dentro da organização cultural e social de uma determinada comunidade. 
É em função dessas compreensões que a Etnomatemática vem funcionando como contraconduta e, ao mesmo tempo, como mecanismo de controle dos corpos pedagógicos desses professores/estudantes indígenas. Suas discussões durante a formação acadêmica, o olhar posicionado quando retornam para suas comunidades, as pesquisas que desenvolvem sobre a temática: "saber tradicional matemático" constitui relações de poder entre esses professores/estudantes indígenas com a própria Universidade, bem como com as estruturas políticas e educacionais que mantêm a escola indígena e os sujeitos que dela fazem parte.

Nesse sentido, para Larrosa (2011, p. 66) "não se trata, então, de diferenciar o que há de verdadeiro, de fictício [...] no discurso, mas de determinar as regras discursivas nas quais se estabelece o que é verdadeiro, o que é fictício". É nesse sentido que se constituem as relações de poder, o disciplinamento dos sujeitos, e, nesse caso, do corpo pedagógico do professor/estudante indígena. As práticas sociais analisadas por Foucault (podendo pensar a escola, a universidade) "[...] são máquinas óticas que produzem, ao mesmo tempo, o sujeito que vê e as coisas visíveis. E máquinas enunciativas que produzem, ao mesmo tempo, significantes e significados" (LARROSA, 2011, p. 66).

O que se tem nas narrativas dos sujeitos de pesquisa é a constituição da Etnomatemática enquanto uma estratégia de subversão dessas máquinas óticas e de como elas vêm produzindo os sujeitos que veem e as coisas visíveis. A Etnomatemática funciona como uma regra discursiva que institui outra verdade em relação à Matemática ensinada nas escolas das aldeias, pois compreende e reconhece não só o saber tradicional do pensamento matemático dos povos indígenas, mas sua funcionalidade dentro de determinadas organizações sociais, como é o caso das comunidades indígenas.

Com isso verifica-se que a Etnomatemática possibilita a produção de mecanismos de controle, de governamento, pois conduz os sujeitos à visibilidade desse saber e institui também, no corpo pedagógico dos professores indígenas, estratégias de subversão do currículo, bem como problematiza outras formas de se conduzir e de conduzir a conduta do outro.

Conduzir a conduta do outro, pois há uma evidência nas falas dos professores/ estudantes indígenas participantes desta dissertação que aponta para suas práticas pedagógicas, pois buscam em suas aulas expor o pensamento matemático do seu povo. Institui sobre os estudantes com quem atua o olho do poder, em que esses 
estudantes precisam necessariamente conhecer ambos os processos de contagem, tanto do seu povo, quanto o do não indígena.

Ao adotar neste estudo lentes foucaultianas, não é adequado entender essa prática pedagógica na ordem do bem nem do mal, mas como práticas discursivas que instituem regimes de verdade. Esses regimes discursivos, como mecanismo para a produção de si, produção da subjetividade tanto do professor indígena, quanto dos estudantes indígenas.

Segundo Fischer (2012, p. 74), com base nos estudos foucaultianos, "[...] nada há por trás das cortinas, nem sob o chão que pisamos. Há enunciados e relações, que o próprio discurso põe em funcionamento". O discurso sempre se produz por meio das relações de poder, sendo este constitutivo da realidade e produz, como o poder, inúmeros saberes (FISCHER, 2012).

Na tentativa de realizar uma análise genealógica com inspiração foucaultiana, compreende-se que o processo de escolarização dos professores/estudantes indígenas, sujeitos desta pesquisa, influenciou sua prática docente, bem como constitui práticas discursivas instituídas como verdade sobre seus corpos pedagógicos. No entanto, ao ingressarem no projeto Açaí e darem continuidade em sua formação por meio do curso de Licenciatura em Educação Básica Intercultural, puderam ressignificar a docência, criando estratégias de conduta de si, assim como a condução do outro, nesse caso, os estudantes indígenas, sem ao mesmo tempo romper com quem os conduz.

\section{DAS CONCLUSÕES PROVISÓRIAS}

Diante das possibilidades do pesquisar com povos indígenas de Rondônia, as propostas metodológicas desenvolvidas durante a produção dessas dissertações de mestrado, nos possibilitou perceber que a produção de dados junto a esses grupos étnicos está articulada, nesse caso, ao relacionamento também que pesquisador e pesquisadora estabelecem com os sujeitos participantes da pesquisa.

Essas questões acontecem também no momento da produção de dados com os participantes indígenas de Rondônia - Crianças Arara-Karo e os professores e professoras estudantes do Curso de Licenciatura em Educação Básica Intercultural, pois, numa perspectiva foucaultiana, a partir do momento que o pesquisador (a) se desloca e se desenquadra, permite se fazer sujeito por meio das relações que estabelece com o outro. Constitui-se por meio de si mesmo e dos outros. 
Além disso, para Foucault (1979), é importante entender que existem várias verdades para determinados acontecimentos, e observar as relações que se estabelecem enquanto relações de força. Afinal de contas os sujeitos se constituem enquanto história e, ao mesmo tempo, são constituídos por ela.

Lentes foucaultianas possibilitam visualizar outros pontos de vista sobre as práticas de si produzidas nos espaços escolares e nos sujeitos que o frequentam. Pensar, por exemplo, nas resistências, ou não, do papel que o ensino de matemática exerce nas subjetivações dentro do espaço escolar.

De acordo com Foucault (1979), essa relação se dá mediante o dirigir a conduta do outro. Essas relações são móveis, podem modificar-se, sendo reversíveis e instáveis, ocorrendo, portanto, entre sujeitos livres. Analogamente coloca-se sob suspeita o funcionamento do poder que se estabelece nas relações entre indígenas, entre indígenas e não indígenas, das (in)visibilidades dos sujeitos a serem pesquisados. Foucault (2011, p. 147) ressalta que a "[...] disciplina define cada uma das relações que o corpo deve manter com o objeto que manipula. Ela estabelece cuidadosa engrenagem entre um e outro", ou em outras palavras "[...] a disciplina fabrica indivíduos, ela é a técnica específica de um poder que toma os indivíduos ao mesmo tempo como objetos e como instrumentos de exercício" (FOUCAULT, 1979, p. 164). Essas técnicas de disciplinamento trazem consigo "características de nosso próprio regime de verdade".

Assumimos neste trabalho um compromisso de cunho político, acadêmico e social e, desse modo, buscamos em nossas escritas aproximar os sujeitos atuantes como atores também da escrita do trabalho. É interessante apontar que as articulações metodológicas possibilitadas pelo contexto de vivência com os atores dessas dissertações foram produzidas, pensadas e negociadas a partir da própria experiência do estar com o outro. Produzir um trabalho, dados, escrita, são questões relacionadas ao estar com o outro, das articulações por meio da escuta, das atenções dadas ao contexto que se pesquisa. Diante dessas problematizações, é que tais possibilidades metodológicas produzidas em ambas as dissertações tornaram-se possíveis, constituíram-se como escrita acadêmica.

\section{REFERÊNCIAS}

ALVES, Rozane Alonso. Infância indígena: narrativas das crianças Arara-Karo na região amazônica. 2014. Dissertação (Mestrado em Educação)- Universidade Federal do Rio Grande do Sul (UFRGS), Porto Alegre, RS, 2014. 
ANDRADE, S. S. A entrevista narrativa ressignificada nas pesquisas educacionais. In: MEYER, D. E.; PARAÍSO, M. A. (Org.). Metodologias de pesquisas pós-críticas em educação. Belo Horizonte: Mazza Edições, 2012. p. 173-194.

CUNHA, Susana Rangel Vieira da. Como vai a arte na Educação Infantil? Educação-arteeducação. In: RODRIGUES, M. B. Castro; DALLA ZEN, M. I. (Org.). Tópicos educacionais I. Porto Alegre, RS: Editora UFRGS, 2013. p. 31-40.

DUSCHATZKY, Silvia ; SKLIAR, Carlos. O nome dos outros: narrando a alteridade na cultura e na educação. In: BONDIA, Jorge Larrosa; SKLIAR, Carlos (Org.). Habitantes de Babel: políticas e poéticas da diferença. Belo Horizonte: Autêntica, 2001.

FISCHER, Rosa Maria Bueno. Trabalhar com Foucault: arqueologia de uma paixão. Belo Horizonte: Autêntica, 2012.

FOUCAULT, M. A ordem do discurso: aula inaugural no Collége de France, pronunciada em 2 de dezembro de 1970. 21. ed. São Paulo: Loyola, 2011.

. História da sexualidade 3: o cuidado de si. Rio de Janeiro: Graal, 1985.

. Microfísica do poder. Rio de Janeiro: Edições Graal, 1979.

LARROSA, Jorge. Tecnologias do eu e educação. In: SILVA, Tomaz Tadeu da (Org.). O sujeito da educação: estudos foucaultianos. 12. ed. Petrópolis, RJ: Vozes, 2011.

MARTINS FILHO, Altino; PRADO, Patrícia. Das pesquisas com crianças: complexidades da infância. São Paulo: Autores Associados, 2011.

MEYER, Dagmar Estermann; PARAÍSO, Marlucy Alves. Metodologias de pesquisas pós-críticas ou sobre como fazemos nossas investigações. In: MEYER, Dagmar Estermann; PARAÍSO, Marlucy Alves (Org.). Metodologias de pesquisas pós-críticas em educação. Belo Horizonte: Mazza Edições, 2012. p. 15-22.

MEYER, Dagmar Estermann. Abordagens pós-estruturalistas de pesquisa na interface educação, saúde e gênero: perspectiva metodológica. In: MEYER, Dagmar Estermann; PARAÍsO, Marlucy Alves (Org.). Metodologias de pesquisas pós-críticas em educação. Belo Horizonte: Mazza Edições, 2012. p. 47-61.

NUNES, Angela. No tempo e no espaço: brincadeiras das crianças A 'uwe-Xavante. In: SILVA, Aracy; MACEDO, Ana Vera; NUNES, Angela (Org.). Crianças indígenas: ensaios antropológicos. São Paulo: Global, 2002. p. 64-100.

PARAÍSO, Marlucy Alves. Metodologias de pesquisas pós-críticas ou sobre como fazemos nossas investigações. In: MEYER, Dagmar Estermann; PARAísO, Marlucy Alves (Org.). Metodologias de pesquisas pós-críticas em educação. Belo Horizonte: Mazza Edições, 2012. p. 23-45. 
PEREIRA, Rita Marisa Ribes. Pesquisa com crianças. In: PEREIRA, Rita Marisa Ribes; MACEDO, Nélia Mara Rezende (Org.). Infância em pesquisa. Rio de Janeiro: Nau, 2012.

SANTOS, Jonatha Daniel dos. Saberes etnomatemáticos na formação de professores indígenas do curso de licenciatura intercultural na Amazônia. 2015. Dissertação (Mestrado em Educação em Ciências e Matemática) - Pontifícia Universidade Católica do Rio Grande do Sul (PUC-RS), Porto Alegre, RS, 2015.

SARMENTO, Manuel Jacinto. Conhecer a infância: os desenhos das crianças como produções simbólicas. In: MARTINS FILHO, Altino; PRADO, Patrícia (Org.). Das pesquisas com crianças: complexidades da infância. São Paulo: Autores Associados, 2011.

SKLIAR, Carlos. Pedagogia (improvável) da diferença - e se o outro não estivesse aí? Rio de Janeiro: DP\&A, 2003.

TOMAS, Catarina. Há muitos mundos no mundo: cosmopolitismo, participação e direitos da criança. Porto, Portugal: Edições Afrontamentos, 2011.

TREVISAN, Gabriela de Pina. Amigos(as) e namorados (as): relacionamentos entre pares. [s.d.]. Disponível em: <http://repositorio.esepf.pt/bitstream/20.500.11796/1025/2/artigo_gabriela_encontro_final.pdf>. Acesso em: mar. 2014.

VEIGA-NETO, Alfredo. Foucault \& a educação. Belo Horizonte: Autêntica, 2007.

\section{Sobre os autores:}

Rozane Alonso Alves: Doutoranda do Programa de Pós-Graduação em Educação da Universidade Católica Dom Bosco (UCDB), Bolsista Taxa PROSUP. Licenciada em Pedagogia (UNIR) e Mestre em Educação pela UFRGS. Professora do Instituto Federal Goiano (IF Goiano). E-mail: rozanealonso@gmail.com

Jonatha Daniel dos Santos: Doutorando do Programa de Pós-Graduação em Educação da Universidade Católica Dom Bosco (UCDB), Bolsista Taxa PROSUP. Licenciado em Matemática (UNIR) e Mestre pela Pontifícia Universidade Católica do Rio Grande do Sul (PUC-RS). E-mail: dholjipa@gmail.com

\section{Recebido em 30 de janeiro de 2017}

Aprovado para publicação em 6 de fevereiro 2017 